\title{
Endosomal recycling to the surface mediated by Gpa1 and PI3-Kinase is inhibited by glucose starvation
}

\author{
Kamilla ME. Laidlaw*1, Katherine M. Paine ${ }^{* 1}$, Daniel D. Bisinski ${ }^{1,2}$, Grant Calder ${ }^{3}$, Chris MacDonald ${ }^{1,4}$ \\ ${ }^{*}$ Equal contribution \\ 1 York Biomedical Research Institute and Department of Biology, University of York, York, UK \\ ${ }^{2}$ Present address: Department of Biology \& Chemistry, University of Osnabrück, Osnabrück, Germany \\ ${ }^{3}$ Imaging and Cytometry Laboratory, Bioscience Technology Facility, Department of Biology, University of York, UK \\ 4 Correspondence: Email: chris.macdonald@york.ac.uk Tel: +44 (0) 1904328609
}

\begin{abstract}
Cell surface protein trafficking is regulated in response to nutrient availability, with multiple pathways directing surface membrane proteins to the lysosome for degradation in response to suboptimal extracellular nutrients. Internalised protein and lipid cargoes recycle back to the surface efficiently in glucose replete conditions, but this trafficking is attenuated following glucose starvation. We find cells with either reduced or hyperactive phosphatidylinositol 3-kinase activity are defective for recycling. Furthermore, we find the yeast $G a$ subunit $G$ pa1, which localises to endosomes and functionally couples with phosphatidylinositol 3-kinase, is required for surface recycling of cargoes. Following glucose starvation, nuclear translocation of Mig1 increases GPA2 levels and inhibits recycling, potentially by diverting Gpa1 to the surface and interfering with its endosomal role in recycling. Glucose privation therefore triggers a survival mechanism to increase retention of surface cargoes in endosomes and promote their lysosomal degradation.
\end{abstract}

\section{INTRODUCTION}

The surface localisation and activity of plasma membrane (PM) proteins can be regulated by the balance of action between endocytic trafficking pathways. Clathrin dependent and independent mechanisms internalize proteins from the PM, which then transit through different compartments en route to the lysosome for degradation. Various recycling mechanisms transport cargoes back to the surface, providing multiple regulatable steps to fine tune the surface protein environment in response to external conditions. Yeast has been a useful model organism to uncover conserved trafficking mechanisms of surface proteins. Upon internalisation from the yeast PM, surface cargoes can be sorted to the lysosomelike vacuole, in a process that involves cargo ubiquitination, mediated by E1-E2-E3 enzyme cascade in collaboration with competing trafficking bioRXiv Laidlaw, Paine et al. 2021 adaptors (MacDonald et al., 2020; Sardana and Emr, 2021). Ubiquitinated cargoes are recognised at multivesicular bodies (MVBs) by the Endosomal Sorting Complex Require for Transport (ESCRT) apparatus, which also package cargo destined for degradation into intraluminal vesicles (Laidlaw and MacDonald, 2018). Proteins that are not destined for degradation can recycle back to the surface, including a retrograde route that traffics material to the surface via the trans-Golgi network (TGN) using dedicated machineries that interact with recycled cargoes (Chen et al., 2019). Recycling in animal cells can also occur directly from early endosomes or indirectly, first traversing defined recycling endosomes (MacDonald and Piper, 2016). Endosomal organisation and recycling mechanisms in yeast are less clear (Ma and Burd, 2019a), but work using the yeast exocytic vSNARE protein Snc1 revealed multiple endosomal transport steps regulate Snc1 trafficking back to the PM (Ma et al., 2017; Ma and Burd, 2019b; Best et al., 2020). It was recently shown that although retrograde recycling is perturbed by deubiquitination (Xu et al., 2017), cargo recycling of some nutrient transporters is triggered by deubiquitination (MacDonald and Piper, 2017). Genetic dissection of this latter pathway implies recycling is controlled at the transcriptional and metabolic level, suggesting that early endocytic trafficking decisions contribute to the eventual downregulation of surface cargoes in response to nutritional cues.

During periods of nutritional stress, multiple mechanisms involving surface cargoes and endocytic pathways are modulated to promote proliferation, particularly in cancer cells (Selwan et al., 2016; Finicle et al., 2018). Recycling internalised cargoes back to the surface can promote anabolic processes. During starvation, when some such processes are not required, reduced recycling can route surface cargoes to the lysosomal (vacuolar in yeast) degradation pathway instead, to promote catabolism. Conceptually, these pathways can be modulated to drive growth/proliferation appropriate to extracellular nutrient availability. One such example has been elucidated in yeast responding to nitrogen starvation, where increased trafficking to the vacuole is achieved through the amino acid sensing TORC1 complex, 
which activates Rsp5-adaptors via the Npr1 kinase and promotes cargo ubiquitination and degradation (MacGurn et al., 2011). The Rag GTPases integrate with nutrient sensing and TORC1 activity via the EGO complex (Binda et al., 2009; Bonfils et al., 2012; PéliGulli et al., 2015), but in addition appear to regulate recycling via endosomally-localised Ltv1 in response to extracellular Leucine (MacDonald and Piper, 2017). Glucose starvation may also trigger a similar dual regulation of recycling and degradation pathways in yeast, where many metabolic pathways are known to be evolutionarily conserved (Santangelo, 2006). Although the majority of transcriptional changes elucidated in response to suboptimal glucose availability involve alternative carbon pathways, we recently revealed a response that increases trafficking from the surface to the lysosome in response to glucose starvation. Furthermore, recycling back to the surface is reduced when cells are exposed to media lacking sugar (Lang et al., 2014), but the molecular players involved in this response are not fully established.

In high glucose levels, Snf1 (yeast AMPactivated protein kinase, AMPK (Hong et al., 2003)) is inactivated primarily through its dephosphorylation by Reg1-Glc7 (Tu and Carlson, 1994; Sanz et al., 2000). Whilst Snf1 can influence endosomal trafficking during glucose changes in yeast independently (O'Donnell et al., 2015), one key downstream consequence of glucose starvation involves Snf1 activation and regulation of the Mig1 transcriptional repressor (Johnston et al., 1994; Treitel et al., 1998). Mig1 is a zinc finger transcription factor that mediates glucose repression in yeast cells (Nehlin and Ronne, 1990; Lundin et al., 1994) and in response activates alternative metabolic pathways (Schüller, 2003). In addition to this, Mig1 influences membrane trafficking machinery through its repression of clathrin adaptor genes YAP1801 and YAP1802 under glucose replete conditions that stabilise endocytosis levels (Laidlaw et al., 2020). These experiments were performed in media supplemented with the alternative carbon source raffinose, which might provide a distinct osmotic potential that makes direct comparison with the finding that recycling is reduced during carbon withdrawal. Furthermore, the reduced recycling following glucose starvation (Lang et al., 2014) can be bypassed by enforcing cargo ubiquitination in the endomembrane system upstream of MVB sorting (Buelto et al., 2020). This suggests that both the ubiquitin-mediated degradation pathway (MacDonald and Piper, 2016), and the counteracting recycling pathway induced following cargo deubiquitination from ESCRT-localised endosome compartments (MacDonald et al., 2012a, 2015a) are both regulated in response to glucose starvation to collectively promote reduced surface activity and increased vacuolar degradation.

A genetic screen for recycling machinery identified several candidates for glucose-mediated control, including the G-protein coupled receptor
(GPCR) Gpr1 and downstream GTPase Ras2 (MacDonald and Piper, 2017). Gpr1, which is activated by the $\mathrm{Ga}$ subunit Gpa2, activates cAMP signalling in response to glucose through recruiting Ras-GTP to the plasma membrane (Colombo et al., 1998; Broggi et al., 2013). This cAMP signalling cascade in response to glucose causes a protein kinase $A(P K A)$ response and leads to changes in a variety of different targets (Thevelein, 1994; Kraakman et al., 1999). The screen for recycling machinery also implicated a distinct $\mathrm{G} \alpha$ subunit, Gpa1 in recycling (MacDonald and Piper, 2017). Gpa1 is the $\mathrm{Ga}$ subunit of a heterotrimeric $\mathrm{G}$ protein complex also comprised of $G \beta$ and $G y$ subunits Ste $4 p$ and Ste18p, that functions in the pheromone response pathway (Dietzel and Kurjan, 1987; Miyajima et al., 1987; Whiteway et al., 1989). Just as Gpa2 cannot functionally couple with distinct mating GPCRs (Blumer and Thorner, 1990) it is thought that the distinct the $\mathrm{G} \alpha$ subunit $\mathrm{Gpa} 1$ does not regulate Gpr1 directly. In addition to playing a role at the plasma membrane in the pheromone response pathway, Gpa1 interacts with the yeast phosphatidylinositol 3kinase (Vps15 and Vps34) at endosomes (Slessareva et al., 2006; Heenan et al., 2009). The phosphorylation status of a variety of different phosphoinositides (PIs) species regulate membrane trafficking pathways via downstream effectors (Camilli et al., 1996). Phosphoinositide 3-kinases (PI3K) are therefore key regulatory proteins known to control a variety of different membrane trafficking steps (Lindmo and Stenmark, 2006). Vps34, in complex with Vps15, was first identified in yeast as being required for the post-Golgi trafficking of biosynthetic enzymes to the vacuole (Herman and Emr, 1990; Schu et al., 1993; Stack et al., 1993). The generation of phosphatidylinositol 3-phosphates (Ptdlns3P) through Vps34 activity is also required for efficient retrograde traffic from the endosome to the late-Golgi (Burda et al., 2002).

In this study, we use both lipid and protein recycling reporters to show that glucose starvation inhibits endosomal recycling of cargo back to the surface. We show the Ga subunit Gpa1 and PI3K are required for efficient recycling in glucose replete conditions. Following glucose starvation, there is a transcriptional response involving Glc7/Reg1 and Mig1 that increases expression of the $\mathrm{Ga}$ subunit GPA2. We find increasing protein levels of Gpa2, which physically interacts with Gpa1 (Ho et al., 2002), inhibits recycling or various cargoes. We find no evidence of endosomal Gpa2, so propose its inhibitory role in recycling is indirect, potentially by commandeering Gpa1 from endosomal PI3K. Reducing recycling increases endosomal retention and vacuolar degradation of surface cargoes, as a cell survival response to glucose starvation. 


\section{RESULTS}

\section{Glucose starvation inhibits surface recycling}

Previous work has shown that in response to glucose starvation, the yeast AP180 clathrin adaptors are transcriptionally upregulated with a concomitant increase in endocytosis (Laidlaw et al., 2020). Under basal conditions in media lacking methionine, the methionine transporter Mup1 tagged with GFP localises to the plasma membrane (PM), but much of this signal is redistributed to endosomes and the vacuole upon plasmid over-expression of mCherrytagged AP180s: Yap1801-Cherry or Yap1802mCherry (Figure 1A). In contrast, a recycling reporter based on the fusion of the G-protein couple receptor

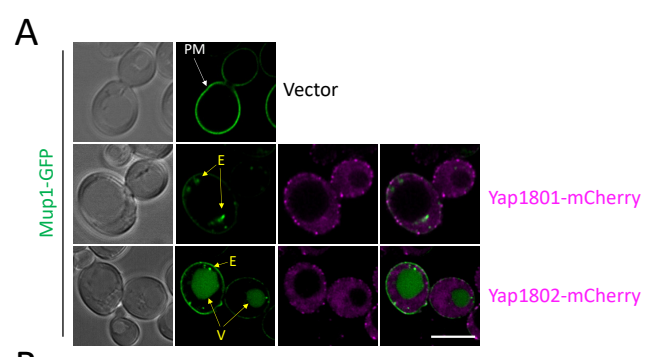

B

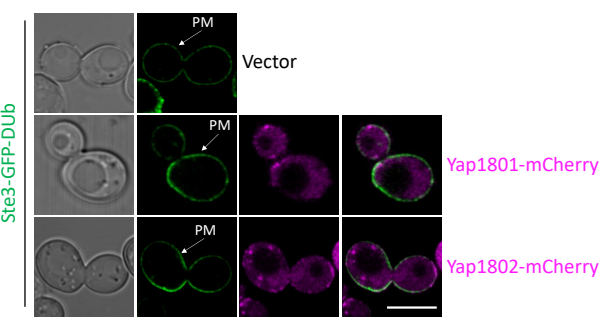

C
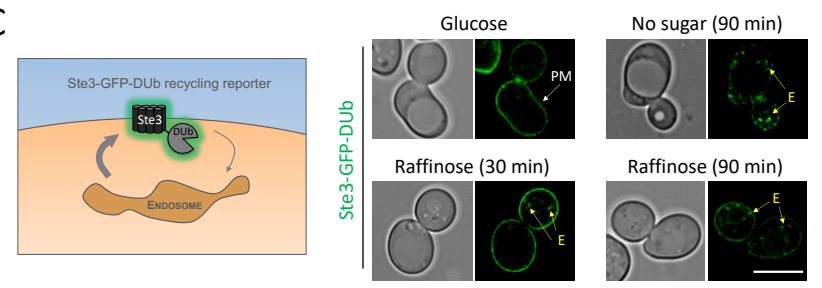

D
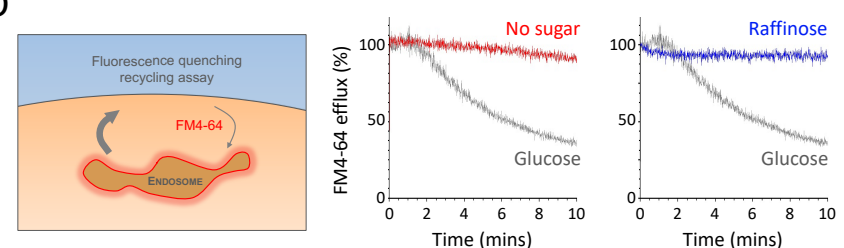

Figure 1: Glucose starvation specifically inhibits recycling A) Confocal imaging of cells expressing Mup1-GFP under control of its endogenous promoter co-expressed with Yap1801-mCherry or Yap1802-mCherry expressed from the CUP1 promoter through addition of $50 \mu \mathrm{M}$ copper chloride for 2 hours. A vector control exposed to copper was also included. B) Cells stably integrated with Ste3-GFP-DUb were exposed to 2 hours copper chloride to induce expression of mCherry tagged versions of Yap1801 and Yap1802, before confocal microscopy. C) Cells expressing Ste3-GFP-DUb from the STE3 promoter were grown under indicated media conditions prior to confocal microscopy. D) Wild-type cells loaded with rich media containing $40 \mu \mathrm{M}$ FM4-64 for 8-minutes before washing and dye efflux measured over time by flow cytometry. Control cells grown in glucose media were compared with 30-minute prior incubation with media lacking any carbon source (red) or media supplemented with raffinose (blue). White arrows indicate exclusive plasma membrane (PM) signal and yellow arrows indicate endosome (E) or vacuole (V) localisation. Scale bar, 5 Hm.
(GPCR) Ste3 tagged with GFP and the catalytic domain of a deubiquitinating enzyme (Stringer and Piper, 2011; MacDonald and Piper, 2017), showed no increase in endosomal localisation following overexpression of yeast AP180s (Figure 1B). This correlates with observations that Ste3-GFP-DUb does not accumulate when endocytosis rates are elevated by the addition of a-factor or at elevated temperature (MacDonald and Piper, 2017). We conclude that although different manipulations increase the rate of endocytosis, the deubiquitination-driven recycling of Ste3-GFP-DUb predominates to maintain an exclusive steady state localisation at the PM. Having established that Ste3-GFP-DUb primarily reports on cell surface recycling, we used this reporter to test whether glucose starvation impacts recycling specifically. Treating the cells in media completely lacking sugar, or by substituting glucose for the alternative carbon course raffinose, results in an accumulation of Ste3-GFP-DUb in intracellular endosomes (Figure 1C). A distinct recycling assay, which measures recycling by efflux of endocytosed fluorescent FM4-64 (Wiederkehr et al., 2000), has previously shown carbon source removal inhibits recycling (Lang et al., 2014). Similarly, we find shifting cells to media lacking sugar or supplemented with raffinose also results in robust inhibition of recycling (Figure 1D). Therefore, although internalization from the plasma membrane increases following glucose starvation (Laidlaw et al., 2020), two dedicated recycling reporters show glucose starvation also triggers a reduction in protein and lipid traffic from endosomes back to the PM. We propose increased internalization and decreased recycling during glucose starvation cooperate to drive vacuolar degradation of cargoes en masse in response to nutritional stress. We set out to explain this recycling response at a molecular level. As both glucose removal and raffinose exhibit defects in recycling, we use raffinose substitution as a means to deprive cells of glucose in downstream experiments, as they cannot readily metabolise this trisaccharide (Fuente and Sols, 1962).

\section{Gpa1-PI3K is required for surface recycling}

A previous genetic screen for novel recycling machinery, based on the mis-localization of Ste3GFP-DUb, (MacDonald and Piper, 2017) identified 89 candidate factors as required for recycling (Figure 2A). To identify any proteins from this list that might inhibit recycling during glucose starvation (Figure 1), a network analysis of all 89 proteins was performed based on both physical and functional associations to reveal a small cluster, containing the glucose regulated receptor Gpr1, and associated factors Ras2 and Gpa1 (Figure 2B). We stably integrated the Ste3GFP-DUb reporter into strains lacking each factor (gpa1 1 , ras2 $\Delta$, and gpr1 $\Delta$ ) and confirmed they exhibit defects in recycling (Figure $2 \mathrm{C}$ ). Although deletion of these genes results in a pronounced mis-localisation phenotype, we also performed flow cytometry 
A

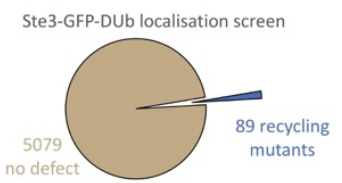

B

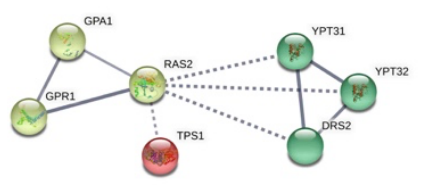

C

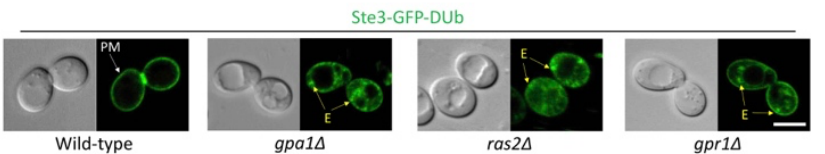

D
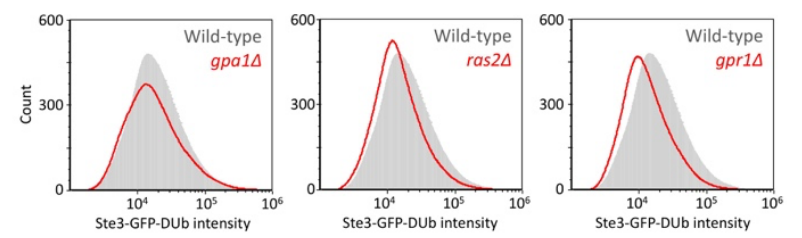

$\mathrm{E}$

$\mathrm{F}$

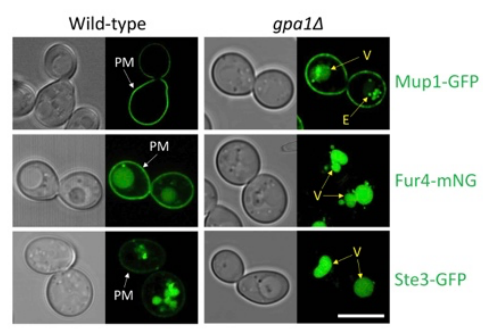

Figure 2: Gpa1 is required for protein and lipid recycling to the surface A) Pie chart representing gene deletions that have no impact on Ste3-GFPDUb recycling (brown), or those that accumulate the reporter in endosomes (blue). B) String pathway analysis was performed on all 89 recycling factor candidates (minimum interaction score $=$ high confidence, 0.700 ) before application of a k-means clustering algorithm to define 9 groups. A small cluster connected by solid lines, representing strongly supported functional and physical associations (yellow) is shown alongside associations with distinct clusters (red and green) shown by broken lines. C) Ste3-GFP-DUb localisation recorded in indicated cells by confocal microscopy. D) Flow cytometry was used to measure Ste3-GFP-DUb fluorescence from approximately 75,000 cells of each indicated mutant (red) and compared with expression in wild-type cells (grey overlay). E) Wild-type (grey) or gpa1 $\triangle$ (red) cells were loaded with FM4-64 for 8-minutes before dye efflux was assessed by flow cytometry over 10-minutes. F) Wild-type and gpa1 1 cells expressing Mup1-GFP, Fur4-mNG or Ste3-GFP were grown to log phase before confocal microscopy to determine localisation. White arrows (exclusive PM) and yellow arrows (vacuole; V) are indicated. Scale bar, $5 \mu \mathrm{m}$.

experiments to confirm that total levels of Ste3-GFPDUb were not elevated to account for additional signal in intracellular compartments (Figure 2D). Although all three candidates are known to localise and function at the plasma membrane, we focussed on the Ga subunit Gpa1 for this study, as it has also been shown to localise to endosomes and activate PI3K (Slessareva et al., 2006), which is involved in various endomembrane trafficking events (Lindmo and Stenmark, 2006; Reidick et al., 2017). We first considered the G-protein subunit Gpa1 might specifically perturb the Ste-GFP-DUb reporter, as it based on the G-protein coupled receptor Ste3. However, we found general recycling of lipids, as assessed by FM4-64 efflux, was also defective in gpa1s mutants (Figure 2E). Furthermore, trafficking of endogenous cargoes to the PM was also perturbed in gpa1 cells. We found the methionine transporter
Mup1 tagged with GFP, which localises exclusively to the PM in wild-type cells, is shifted to endosomes and the vacuole in gpa1s mutants (Figure 2F). Similarly, the plasma membrane signal of the uracil transporter Fur4, tagged with mNeonGreen $(\mathrm{mNG})$, or Ste3 tagged with GFP (but lacking fusion to a deubiquitinating enzyme), was sorted to the vacuole in gpa $1 \Delta$ cells. All of these defects in lipid and protein trafficking are consistent with a role for Gpa1 in surface recycling.

To test if these Gpa1 effects are mediated through $\mathrm{PI} 3 \mathrm{~K}$, we analysed recycling in cells lacking PI3K subunits ( $v p s 15 \Delta$ and vps34A), which both exhibit morphological defects of the vacuolar / endolysosomal system (Figure 3A). Vacuole morphology following FM4-64 staining was difficult to resolve by conventional confocal microscopy but Airyscan microscopy revealed layers of small vacuolar-like structures in both vps15 $\Delta$ and vps34 $\Delta$

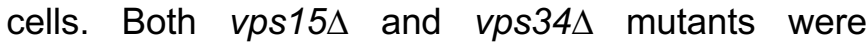

A

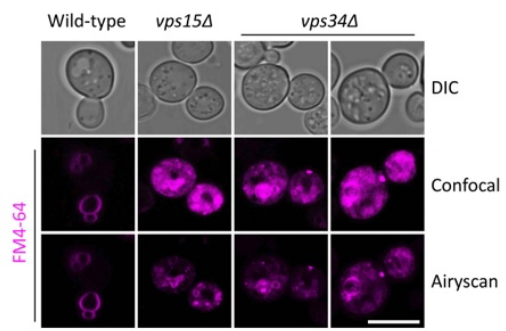

B

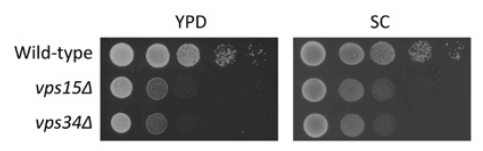

C

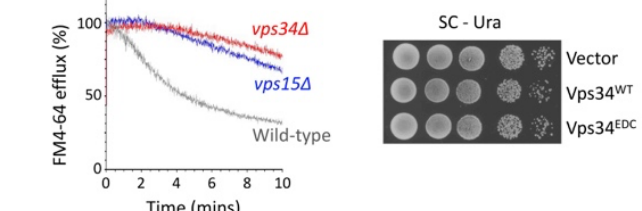

$\mathrm{E}$

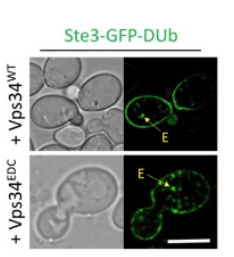

$\mathrm{F}$

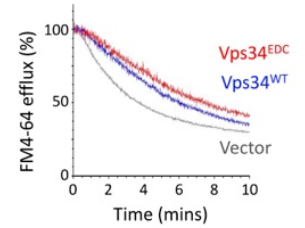

Figure 3: Defined PI3-Kinase activity is required for surface recycling

A) Confocal and Airyscan imaging of wild-type, vps $15 \Delta$ and vps $34 \Delta$ cells first labelled with $10 \mu \mathrm{M}$ FM4-64 for 30 minutes, followed by washing and a 1-hour chase in SC minimal media. B) Indicated cells were grown to log phase, equivalent volumes harvested and a 1 in 10 serial dilution spotted onto YPD and synthetic complete (SC) media and incubated at $30^{\circ} \mathrm{C}$. C) Indicated cells were loaded with $40 \mu \mathrm{M}$ FM4-64 in rich media for 8-minutes, before $3 \times 5$ minute washes and dye efflux measured over time by flow cytometry. D) Wild-type cells transformed with either empty vector, wildtype Vps34 (Vps34 ${ }^{\mathrm{WT}}$ ) or hyperactive Vps34 (Vps34 ${ }^{\mathrm{EDC}}$ ) plasmids were grown to mid-log phase, equivalent volumes harvested and grown on SC media lacking uracil (SC - Ura) at $30^{\circ} \mathrm{C}$. E) Wild-type cells co-expressing Ste3-GFPDUb with either Vps34wT or Vps34EDC were imaged using confocal microscopy. F) FM4-64 efflux following 8-minutes loading was assessed in wild-type cells expressing Vps34 ${ }^{W T}$ (blue) or Vps34 EDC (red) from a plasmid. Yellow arrows indicate endosomes (E) Scale bar, $5 \mu \mathrm{m}$. 
confirmed to have a growth defect at $30^{\circ} \mathrm{C}$ (Figure 3B) before we revealed that $v p s 15 \Delta$ and $v p s 34 \Delta$ cells are severely defective in their ability to recycle internalised FM4-64 dye (Figure 3C). This supports the notion that yeast $\mathrm{PI} 3 \mathrm{~K}$ in collaboration with $\mathrm{Gpa} 1$ is responsible for recycling from endosomes to the surface. To further corroborate this model, we employed a hyperactive version of Vps34, termed Vps34 ${ }^{\mathrm{EDC}}$ (harbouring R283E, A287D, Y501C point mutations) that was recently used to show Ptdlns $3 P$ production is rate limiting for some, but not all, membrane trafficking pathways (Steinfeld et al., 2021). We found that unlike deletion of $\mathrm{PI} 3 \mathrm{~K}$, increased expression of $\mathrm{Vps} 34^{\mathrm{WT}}$ or Vps $34^{\mathrm{EDC}}$ had no effect on growth at $30^{\circ} \mathrm{C}$ (Figure 3D). However, expressing hyperactive $\mathrm{Vps} 34^{\mathrm{EDC}}$ was sufficient to perturb recycling of Ste3-GFP-DUb (Figure 3E), and the lipid dye FM4-64 (Figure 3F), suggesting elevated Ptdlns $3 \mathrm{P}$ production deregulates recycling, but to a lesser degree than in cells lacking PI3K activity.

\section{Reg1 regulates recycling at transcriptional level}

Gpa1 localises to the plasma membrane and endomembrane compartments (Slessareva et al., 2006; Dixit et al., 2014), this includes some colocalization with the late endosome marker Vps4, and to a lesser degree, the TGN marker Sec7 (Figure 4A). We found there was a subtle defect in Ste3-GFPDUb recycling upon over-expression of Gpa1mCherry (Figure 4B), suggesting both $\mathrm{PI} 3 \mathrm{~K}$ and Gpa1 levels need to be finely tuned for efficient recycling back to the surface. The small amount of intracellular Ste3-GFP-DUb colocalised with Gpa1mCherry, suggesting a trafficking block in endosomes from which recycling occurs. Deletion of the recycling factor $R C Y 1$ results in more prominent accumulations of Ste3-GFP-DUb inside the cell (MacDonald and Piper, 2017), some of which colocalise with Gpa1mCherry but there are also distinct populations. This might be explained by the recycling defects in $r c y 1 \Delta$ cells perturbing an earlier stage in the pathway that accumulates Ste3-GFP-DUb in aberrant endosomal compartments prior to the recycling step Gpa1 regulates. Expressing a constitutively active version (Gpa1 ${ }^{\mathrm{Q} 323 \mathrm{~L}}$-mCherry) caused more severe defects in Ste3-GFP-DUb (Figure 4C), again with internalised recycling reporter accumulating in endosomes marked by Gpa1. Recycling defects induced by Gpa1 ${ }^{\mathrm{Q} 23 \mathrm{~L}}$ can be explained by its ability to regulate phosphoinositide levels of the endosome that one might predict need to be regulated for all endosomal trafficking, but it does not explain if Gpa1 integrates with recognition of glucose starvation. However, Gpa1 ${ }^{\mathrm{Q} 323 \mathrm{~L}}$ has been used to systematically screen all yeast deletion mutants for effectors, in the study that revealed Gpa1 functionally couples with PI3K subunits Vps15 and Vps34 (Slessareva et al., 2006). This screen revealed deletion of the glucose-related phosphatase REG1 suppresses the Gpa1 ${ }^{\text {Q323L }}$ response and was in fact the top scoring mutant of the screen, with effects even larger than either vps15 $\Delta$ or $v p s 34 \Delta$ cells (Figure 4D). In support of the idea that Reg1 functions in the same pathway as Gpa1, recycling of Ste3-GFP-DUb (Figure 4E) and FM4-64 (Figure 4F) are perturbed in reg1 $1 \Delta$ cells. We note, however, that no obvious recycling defects were observed in cells lacking the SNF3 glucose sensing component.
A

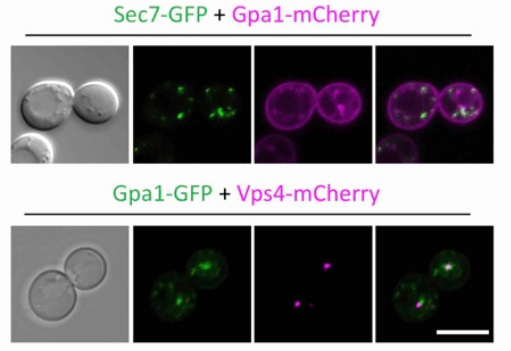

B

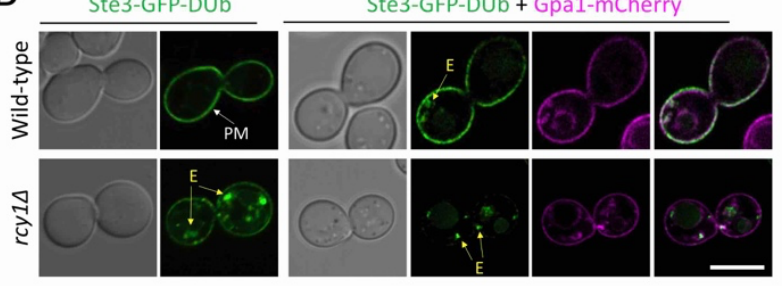

C

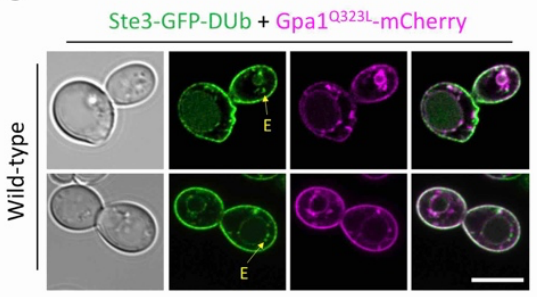

D

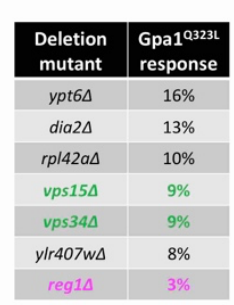

E

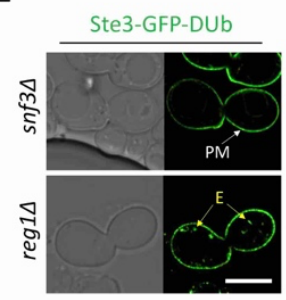

F

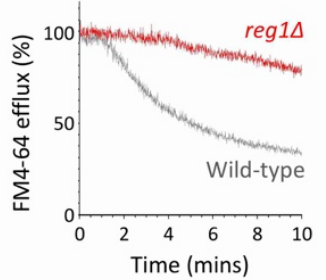

Figure 4: Reg1 is a proposed upstream Gpa1 regulator in recycling A) Confocal microscopy of wild-type cells co-expressing Sec7-GFP and Gpa1-mCherry (top) and Gpa1-GFP and Vps4-mCherry (bottom). B) Wild-type and rcy1 $\Delta$ cells expressing Ste3-GFP-DUb with and without Gpa1-mCherry were imaged

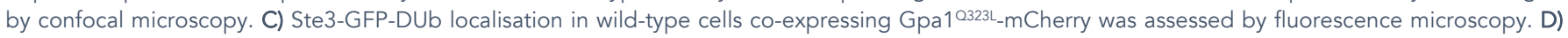
Top scoring mutants from a Gpa ${ }^{\mathrm{Q} 323 \mathrm{~L}}$ mating response screen (Slessareva et al., 2006) are shown, with PI3K mutants (green) and reg1 $\Delta$ (magenta) highlighted. E) Confocal microscopy of snf3 $\Delta$ and reg1 $\Delta$ cells stably expressing Ste3-GFP-DUb. F) Wild-type (grey) and reg1 $\Delta$ (red) cells were incubated with rich media containing $40 \mu \mathrm{M}$ FM4-64 for 8-minutes before washing and dye efflux measured by flow cytometry. Scale bar, $5 \mu \mathrm{m}$. 

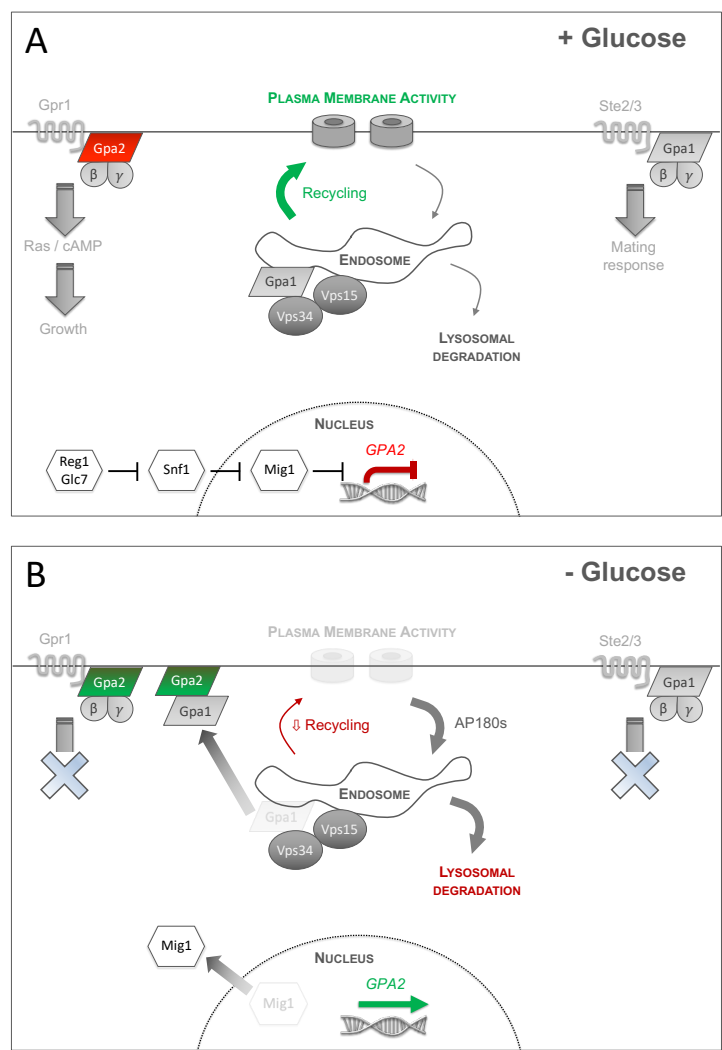

Figure 5: Model for glucose mediated control of cargo recycling A) In glucose rich conditions, metabolism of the cell is maintained to promote growth, in part through the CAMP synthesis pathway sensed through the GPCR Gpr1 and heterotrimeric G protein alpha subunit, Gpa2. In glucose conditions, we propose GPA2 expression is suppressed via the established glucose repression pathway involving Glc7/Reg1 > Snf1 > Mig1. The pheromone signalling and mating pathway, controlled through haploid specific GPCRs Ste2/Ste3 also function at the plasma membrane via the G protein alpha subunit, Gpa1. Gpa1 also has a function at endosomes, with PI3Kinase subunits Vps15/Vps34 producing Ptdlns3P. Surface recycling of plasma membrane cargoes is efficient in glucose replete conditions, via an active and efficient recycling pathway from endosomes back to the surface. B) Glucose starvation triggers several metabolic changes, including growth arrest sensed via Gpr1. This is accompanied by a reduction in mating response, as the Ste $2 / 3$ receptors are downregulated. The Glc7 > Snf1 pathway results in dephosphorylation and translocation of nuclear repressor Mig1. In consequence to this, the yeastAP180 clathrin adaptors are transcriptionally upregulated and induce higher levels of internalization from the plasma membrane. Concomitantly, levels of GPA2 are increased, which we propose acts as an inhibitor of Gpa1-mediated recycling, potentially through sequestering more Gpa1 at the plasma membrane and therefore decamping from PI3kinase at the endosome and disrupting the lipid organisation required to efficiently promote recycling.

Although Reg1 has been shown to directly regulate the phosphorylation status of Gpa1 (Clement et al., 2013), we considered an alternative hypothesis (Figure 5) based on the better characterised role of Reg1 with the essential phosphatase Glc7 as a negative regulator of glucose repressed genes (Tu and Carlson, 1994, 1995). Glc7-Reg1 interacts physically with the yeast AMPK family member Snf1, to maintain its dephosphorylation and inactivation in glucose conditions (Ludin et al., 1998; Sanz et al., 2000; Hong et al., 2005). As Snf1 is well established to regulate the Mig1 transcriptional repressor in response to glucose levels (Johnston et al., 1994; Vallier and Carlson, 1994; Treitel et al., 1998), we considered a model that would predict that in glucose replete conditions, where Gpa1-mediated recycling occurs efficiently via PI3K, activity of Reg1 and the downstream transcriptional regulator Mig1 would repress expression of a recycling inhibitor (Figure $5 A)$. We went on to identify one candidate inhibitor (discussed below): the $\mathrm{Ga}$ subunit Gpa2, which physically and genetically interacts with Gpa1 (Xue et al., 1998; Ho et al., 2002) that we propose fulfils the function of Gpa1-recycling inhibitor. This model would predict that deletion of MIG1, and the MIG2 repressor that it functions with (Lutfiyya et al., 1998; Westholm et al., 2008), would phenocopy the defective recycling observed followed by glucose starvation or in either reg1A or gpa1A cells. As a glucose responsive inhibitor, transcript levels of GPA2 would increase following glucose starvation, and consequently higher levels of Gpa2 would inhibit Gpa1-recycling (Figure 5B). We speculate that the plasma membrane localised Gpa2 may sequester a larger portion of Gpa1 at the surface thereby reducing levels at endosomes and hampering its capacity to regulate the PI3K activity, which needs to be finely tuned for recycling (Figure 3).

\section{Gpa2 inhibits surface recycling}

We find recycling defects of gpa $1 \Delta$ cells are phenocopied in reg1A mutants (Figure 2C, 2E, 4E, $4 \mathrm{~F})$. We reasoned if the role of Reg1 in recycling is through is via its conventional role at a transcriptional level, involving Glc7 > Snf1 > Mig1/2, then recycling defects of reg1 $1 \Delta$ cells would also be phenocopied in mig1 $1 \Delta$ mig2 $\Delta$ mutant cells. Alternatively, if recycling is efficient in mig1 $\Delta$ mig2 $\Delta$ cells, a direct role between Reg1, and its substrate Gpa1 (Clement et al., 2013), would best explain our data. Mig1 is a glucose sensitive transcriptional repressor that rapidly translocates from the nucleus when cells are shifted to raffinose media (Figure 6A, 6B, S1). Many glucose repressed genes are transcriptionally upregulated

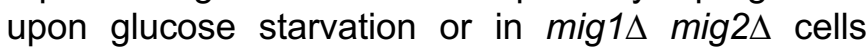
lacking the repressors (Westholm et al., 2008). As mig1s mig2 $\Delta$ mutants exhibit perturbed Ste3-GFPDUb recycling (Figure $6 \mathrm{C}$ ), we assume recycling defects in reg1s mutants are explained via a transcriptional response, as discussed (Figure 5). In order to identify genes transcriptionally controlled by Reg1>Mig1 that inhibit Gpa1-mediated recycling, we cross-referenced a list of genes predicted to be repressed by Mig1 (Wollman et al., 2017) with the physical interactome of Gpa1 to reveal only one candidate, Gpa2 (Figure 6D). To test whether GPA2 was a bona fide target gene for Mig1 repression controlled by glucose we performed qPCR experiments. Firstly, we revealed that GPA1 transcript levels are unchanged in response to Mig1-repression or available glucose. In contrast, the proposed Gpa1inhibitor GPA2 is transcriptionally upregulated $\sim 2.0 \pm$ 0.3 fold in mig $1 \Delta$ mig $2 \Delta$ cells and $\sim 6.4 \pm 0.7$ fold upon a shift to raffinose for 1-hour (Figure 6E). This transcriptional profile is consistent with overexpression of a Gpa1-recycling-inhibitor. Similarly, 
A

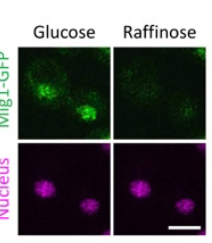

C

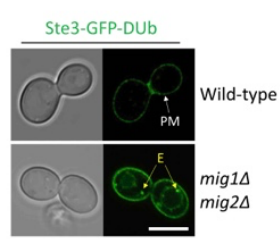

$\mathrm{E}$

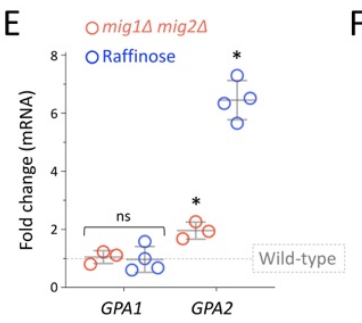

D

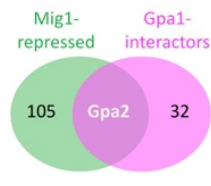

$\mathrm{F}$

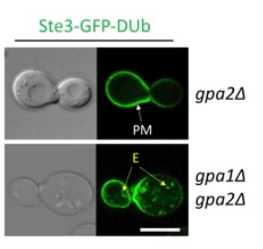

G

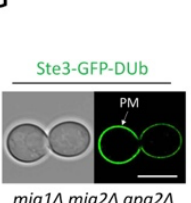

$\mathrm{H}$

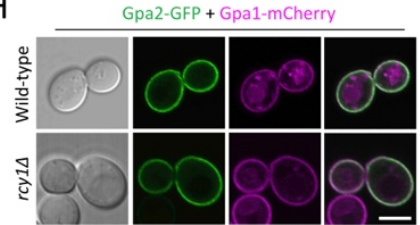

Figure 6: Glucose and Mig1 control expression of GPA2 recycling inhibitor A) Confocal microscopy of wild-type cells co-expressing Mig1-GFP (green) and $\mathrm{Nrd1}$-mCherry as a nuclear marker (magenta) under glucose replete conditions and after 5-minutes raffinose treatment. B) The percentage of nuclear Mig1-GFP signal under glucose and raffinose conditions was quantified (see methods). * indicates unpaired Holm-Sidak $t$-test ( $p<$ 0.0001). C) Confocal microscopy of wild-type and mig1 $1 \Delta$ mig $2 \Delta$ cells expressing Ste3-GFP-DUb. D) Venn diagram of Mig1-repressed candidates (green) and proteins that physically interact with Gpa1 (magenta). E) RTqPCR was used to measure transcript levels of indicated genes, compared to $A C T 1$, in wild-type versus mig $1 \triangle$ mig $2 \Delta$ (red) and wild-type cells grown in glucose versus 60-minutes raffinose media (blue). Unpaired Holm-Sidak t-tests showed GPA1 levels were not significantly (ns) altered in either experiment ( $p=0.748$ and 0.907 , respectively) but levels of GPA2 increased in both mig1 $\triangle$ mig2 $2(p=<0.001)$ and raffinose $(p=<0.000001)$. F) Confocal microscopy of gpa $2 \Delta$ and gpa $1 \Delta$ gpa $2 \Delta$ expressing Ste3-GFPDUb. G) Ste3-GFP-DUb localisation was recorded in mig1 $1 \Delta$ mig $2 \Delta$ gpa2 $\Delta$ cells by confocal microscopy. H) Wild-type and rcy $1 \Delta$ cells co-expressing Gpa2-GFP and Gpa1-mCherry under the CUP1 promoter induced by addition of $50 \mu \mathrm{M}$ copper chloride to the media were imaged using confocal microscopy. Scale bar, $5 \mu \mathrm{m}$.

deletion of the proposed inhibitor exhibits no defects in Ste3-GFP-DUb recycling (Figure 6F), suggesting only increasing levels of Gpa2 inhibits recycling. We did find gpa1s gpa2s cells are defective for Ste3GFP-DUb recycling, supporting the idea that whilst Gpa1-PI3K is required for recycling, Gpa2 is a downstream regulator. The Ste3-GFP-DUb recycling defects triggered by deletion of MIG1 and MIG2 can be attributed to the induced levels of Gpa2 in these cells, as additionally deleting GPA2 in a mig1 $1 \Delta$ mig $2 \Delta$ background suppresses recycling defects (Figure $6 \mathrm{G})$. We found cells expressing Gpa2-GFP localised almost exclusively to the plasma membrane, where

Gpa1-mCherry partially co-localises, in addition to its endosomal localisation. However, this endosomal population shifts to primarily plasma membrane in rcy $1 \Delta$ recycling mutants (Figure $6 \mathrm{H}$ ). In order to test the hypothesis that increased levels of Gpa2 were responsible for defects in recycling, we overexpressed Gpa2-mCherry using the copper inducible CUP1 promoter and found this triggered accumulation of Ste3-GFP-DUb in intracellular compartments (Figure 7A, 7B). Similarly, cells over-expressing Gpa2-GFP have reduced efflux of FM4-64 from the recycling pathway, when compared to control cells expressing the methionine transporter Mup1-GFP (Figure 7C, S2). In addition to the engineered recycling reporter and recycled lipids, we also used the Gpa2-mCherry over-expression system to reveal prominent defects in recycling of the plasma membrane localised GFP tagged transporters Mup1 and Can1, which shift to endosomes and the vacuole (Figure 7D). Gpa2 over-expression induced a reduction of Ste3-GFP from the PM, however we also note that vacuolar sorting, which is typically evident in wild-type cells at steady state, is blocked following Gpa2-mCherry overexpression, and cargo accumulates in prevacuolar structures. We assume overexpression of the $\mathrm{Ga}$ subunit $\mathrm{Gpa} 2$ perturbs

A

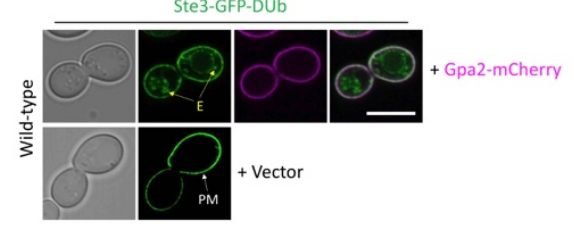

B

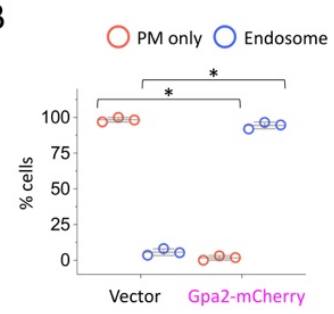

C

D

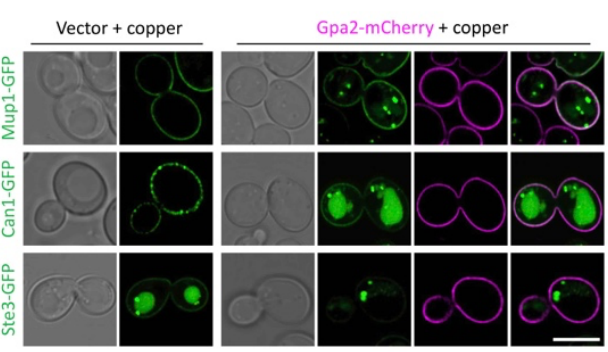

Figure 7: Over-expression of Gpa1 perturbs surface recycling A) Confocal microscopy of wild-type cells expressing Ste3-GFP-DUb with and without Gpa2-mCherry. B) Localisation of Ste3-GFP-DUb in wild-type cells transformed with vector or Gpa2-mCherry at mid-log phase was quantified from $>35$ cells $(n=3)$. Unpaired Students $t$-tests were performed, with asterisk $\left(^{*}\right)$ indicating $p<0.000001$. C) FM4-64 efflux assay was measured from wild-type cells expressing either Gpa2-GFP or Mup1-GFP. Cells were loaded with rich media containing $40 \mu \mathrm{M}$ FM4-64 for 8-minutes before washing and dye efflux measured over time by flow cytometry. D) Wild-type cells expressing the copper inducible Gpa2-mCherry construct, using $50 \mu \mathrm{M}$ copper chloride, and co-expressing either Mup1-GFP, Can1-GFP or Ste3GFP were imaged using confocal microscopy. Scale bar, $5 \mu \mathrm{m}$. 
trafficking of the Ste3 specifically as it is a GPCR, possibly forcing it to adopt a conformation at the PM that is not conducive to MVB sorting, in a manner distinct from general Gpa1-PI3K lipid-mediated trafficking.

To explore whether Gpa2 could function at endosomes directly we performed time-lapse microscopy of cells expressing Gpa2-GFP and only very rarely observed intracellular puncta, however these did not colocalise with Gpa1-mCherry (Figure 8A). We did find strong accumulations of Gpa2-GFP within subdomains of the plasma membrane, which are not observed in cells that localise Mup1-GFP to the PM. We assume these intense accumulations are not eisosomes, for example, as they are fewer in number (only 1 - 2 per cell), and these concentrations partially colocalise with brief pulses of the endocytic dye FM4-64 (Figure 8B). In order to assess Gpa2GFP localisation across the entire cell, we optimised fast yet gentle Apotome Structured Illumination Microscopy (SIM) imaging to capture fluorescence across the entire cell volume, with 42 distinct z-stack slices in both colour channels, captured in only 4.3 seconds. Initial experiments were calibrated using the vacuolar cargo Cos5 (MacDonald et al., 2015a). Cos5-GFP accumulates in the vacuole of wild-type cells but concentrates in class $E$ endosomes in vps25 2 mutant cells (Figure S3), so we used a dual tagged Cos5-GFP-mCherry to optimise processing and noise correction (Figure $8 \mathrm{C}$ ). This technique was then used to perform 4D Apotome SIM microscopy
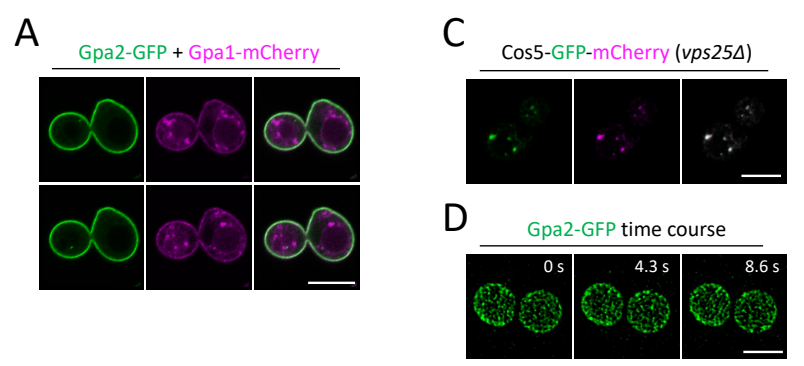

B

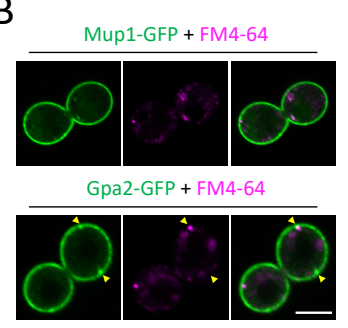

$\mathrm{E}$

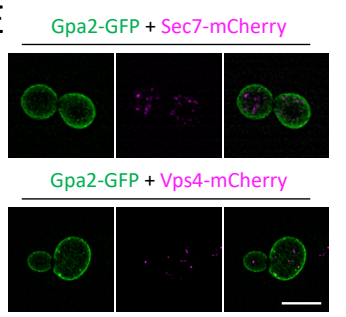

Figure 8: Gpa2 localises to a continuous surface network A) Wild-type cells co-expressing Gpa2-GFP and Gpa1-mCherry were imaged by confocal microscopy. B) Cells expressing either Mup1-GFP or Gpa2-GFP were labelled with $40 \mu \mathrm{M}$ FM4-64 for 3 minutes followed by quenching of extracellular dye with $2.4 \mu \mathrm{M}$ SCAS and confocal imaging. C) 4D Apotome SIM experiments were performed for vps $25 \Delta$ cells expressing a dual GFPmCherry tagged Cos5. D) 3D time lapse Apotome SIM microscopy was used to image wild-type cells expressing Gpa2-GFP with 42x $0.126 \mu \mathrm{m}$ z-stack slices to cover fluorescence across depth of cells. Maximum projections of the top $10 \mathrm{z}$-slices are shown for top-focussed, surface labelled signal. E) Imaging was performed as described in (D) for wild-type cells co-expressing Gpa2-GFP with either Sec7-mCherry (upper) or Vps4-mCherry (lower), with maximum intensity projections generated across all 42 z-stack slices for each sample shown. Scale bar, $5 \mu \mathrm{m}$ experiments of wild-type cells expressing Gpa2-GFP, which displays a continuous network distribution pattern across the plasma membrane (Figure 8D). This localisation is reminiscent of the localisation of the Gpa2 associated protein Ras2, and most distinct from the patch-like eisosome example Sur7 from a previous, thorough analysis of the distribution of dozens of plasma membrane localised proteins (Spira et al., 2012). We also employed 4D Apotome SIM to image entire volume of wild-type cells co-expressing Gpa2-GFP with mCherry tagged markers for the trans-Golgi network (TGN) and the multivesicular body (MVB) but found no evidence of intracellular Gpa2-GFP (Figure 8E, S5). As these efforts did not provide strong evidence for Gpa2 localising anywhere other than the surface, we propose the function of higher levels of Gpa2 at the PM during glucose starvation could simply be to appropriate more Gpa1, thereby depriving PI3K of Gpa1 and reducing its capacity to mediate efficient recycling.

\section{DISCUSSION}

Many protein and lipid trafficking itineraries are overhauled following acute nutrient depletion to equilibrate the energy balance of the cell and adjust metabolism appropriately for the change in extracellular conditions. Reduced recycling of material from endosomal compartments back to the plasma membrane benefits the cell by reducing anabolic load. Furthermore, surface proteins that are not recycled can be directed to the vacuolar degradation pathway instead and promote survival via catabolic processes. The division of labour between recycling and degradation pathways is not fully understood. Many surface proteins in yeast routinely accumulate in the vacuole, where fluorescent tags are stable, potentially overinflating the predominance of the well characterised degradation pathway. Ubiquitination of surface cargoes is sufficient to mediate their sorting via the ESCRT-driven multivesicular body pathway (Katzmann et al., 2001; Urbanowski and Piper, 2001; Babst et al., 2002b, 2002a). Most vacuolar cargoes are ubiquitinated by the Rsp5 E3-ligase and its cargo specific adaptors (O'Donnell and Schmidt, 2019; Sardana and Emr, 2021), but other ligases, such as Tul1 and Pib1, also contribute (Reggiori and Pelham, 2002; Li et al., 2015; MacDonald et al., 2017; Yang et al., 2020). Employing a ubiquitination reversal strategy, achieved by fusion of cargo, E3-ligases, or ESCRT-subunits to the catalytic domain of a deubiquitinating enzyme blocks cargo trafficking through the degradation pathway and allows focus on other endosomal trafficking events (Stringer and Piper, 2011; MacDonald et al., 2012b, 2015b). Here, we show that the GPCR Ste3, tagged with GFP and a DUb domain (Ste3-GFP-DUb) recycling is specifically inhibited following glucose starvation, with Ste3-GFPDUb accumulating in endosomes. We assume efficient recycling of Ste3-GFP-DUb in wild-type cells 
maintains steady state signal at the PM, as increased internalization through over-expression of the yeast AP180 adaptors (Figure 1A) or pheromone or temperature is insufficient to accumulate Ste3-GFP. DUb in endosomes (MacDonald and Piper, 2017). Additionally, irrespective of the internalization rates of FM4-64 to endosomes (Vida and Emr, 1995), we find glucose starvation inhibits FM4-64 recycling back to the PM, measured as a percentage of internalised dye that subsequently effluxes (Wiederkehr et al., 2000). Therefore, we conclude that the Ste3-GFP-DUb reporter is a highly specific recycling reporter and that recycling of both protein and lipids is reduced in response to acute glucose starvation.

A genetic screen for defects in Ste3-GFP-DUb recycling implicated the $\mathrm{G} \alpha$ subunit $\mathrm{Gpa1}$ as required for recycling (MacDonald and Piper, 2017), which we confirmed by stably expressing Ste3-GFP-DUb in gpa1s cells, to show recycling is perturbed. Furthermore, gpa1s mutants cannot recycle FM4-64 as efficiently as wild-type cells and display either reduced PMs signal or enhanced vacuolar sorting of various fluorescently tagged cargoes (Figure 2), the latter phenotype could be explained as an indirect consequence of reduced recycling. Gpa1 has a role outside of surface GPCR signalling and can functionally connect with the yeast PI3K, comprised of Vps34 and Vps15, to simulate phosphatidylinositol 3phosphate (Ptdlns3P) synthesis at endosomes (Slessareva et al., 2006). Like gpa1s mutants, we find $\mathrm{PI}$ K mutants are also defective in recycling (Figure 3). In addition to the role of PI3K in vacuolar trafficking of proteins through the biosynthetic (Robinson et al., 1988; Schu et al., 1993) and autophagy (Kihara et al., 2001; Wurmser and Emr, 2002) pathways, Vps34 generation of Ptdlns3P is also required for retrograde transport (Burda et al., 2002) and for the trafficking of proteins internalised from the $\mathrm{PM}$ and trafficked through the multivesicular body (MVB) pathway (Munn and Riezman, 1994; Katzmann, 2003). Our attempts to recover vps $15 \Delta$ and $v p s 34 \Delta$ cells from the Mat $\alpha$ collection, or to generate the mutants by homologous recombination, were unsuccessful. Localisation of the endogenously expressed Ste3GFP-DUb reporter, which is mating-type specific, was therefore not possible. Instead, we performed experiments with Mat A vps $15 \Delta$ and vps $34 \Delta$ mutants, that are both extremely defective in FM4-64 recycling. To further test the role of PI3K in recycling, we took advantage of an optimised hyperactive Vps34 allele that stimulates over-production of Ptdlns3P, which had previously been shown to upregulate retrograde trafficking, perturb late stages of autophagy and have no effect of MVB sorting (Steinfeld et al., 2021). Expression of hyperactive Vps34 resulted in defects in FM4-64 recycling (Figure 3F) suggesting, like the late stages of autophagy, recycling to the surface requires specific Ptdlns3P regulation. This result also implies Gpa1-PI3K mediated recycling is distinct from retrograde trafficking to the Golgi, which is supported by other studies that document distinct routes in yeast (Ma et al., 2017; Best et al., 2020).

Not only do we observe recycling defects following decreased (vps34 $\Delta$ ) or increased (Vps34 ${ }^{\mathrm{EDC}}$ ) PI3K activity but also following decreased (gpa1A) or increased (constitutively active Gpa1 ${ }^{\mathrm{Q} 323 \mathrm{~L}}$ ) Gpa1 activity (Figure 4C). The screen that discovered signalling of $\mathrm{Gpa}{ }^{\mathrm{Q} 323 \mathrm{~L}}$ requires $\mathrm{PI} 3 \mathrm{~K}$ also revealed reg1s cells, which lack the phosphatase subunit Reg1, which acts with Glc7 (Tu and Carlson, 1995; Sanz et al., 2000), gave the largest defect in signalling across all $\sim 5000$ mutants tested (Slessareva et al., 2006). Although Gpa1 phosphorylation status is controlled by glucose associated enzymes (EIm1, Sak1, Tos3 and Glc7-Reg1), this has little impact on GDP or GTP binding (Clement et al., 2013), the latter being required for $\mathrm{PI} 3 \mathrm{~K}$ mediated production of Ptdlns3P (Slessareva et al., 2006). Therefore, we considered if Reg1 was involved in recycling, this could be enacted at the transcription level, where Reg1-Glc7 regulates the transcriptional repressor Mig1 in response to glucose availability (DeVit and Johnston, 1999; Shashkova et al., 2017). In support of this hypothesis, we observe recycling defects in

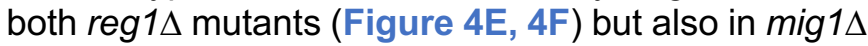
mig2s cells (Figure 6C) lacking downstream transcriptional repressor activity (Schüller, 2003). This suggested expression of an unknown inhibitor of Gpa1-mediated recycling would be de-repressed

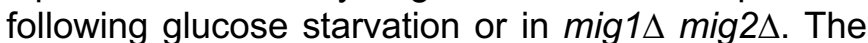
other yeast $\mathrm{Ga}$ subunit Gpa2 was the only candidate recycling inhibitor that both physically interacts with Gpa1 (Ho et al., 2002) but has also been proposed as a gene product repressed by Mig1 (Wollman et al., 2017). We confirmed GPA2 meet these criteria by being transcriptionally upregulated $\sim 6.4 \pm 0.7$ fold following 1-hour raffinose exchange compared with glucose grown cells, and $\sim 2.0 \pm 0.3$ fold in mig1 $\Delta$ mig2 $2 \Delta$ compared to wild-type (Figure 6E). We went on to show that Gpa2 over-expression is sufficient to reduce recycling efficiency of Ste3-GFP-DUb, FM4-64 and various fluorescently tagged surface cargoes (Figure 7). The finding that Ste3-GFP-DUb recycling defects in mig1 $\Delta$ mig2 $\Delta$ can be supressed by further deletion of GPA2 supports the notion that Gpa2 is a recycling inhibitor controlled at the transcriptional level via Mig1 in response to glucose starvation (Figure $6 \mathrm{G}$ ). The exact mechanisms of recycling inhibition via Gpa2 are not known, but we found little evidence of Gpa2 localising to endosomal structures to suggest a direct role with Gpa1-PI3K (Figure 8). Instead, based on the physical interaction of Gpa1 and Gpa2 and the high levels of colocalization at the plasma membrane, we propose elevated levels of surface localised Gpa2 following starvation serve to divert Gpa1 from endosomes, thereby attenuating PI3K activity and recycling (Figure 5B). Although our steady state evidence is not sufficient to conclude that Gpa1 is sequestered by Gpa2 at the surface, we did find an increase of surface localised Gpa1 in the recycling mutant $r c y 1 \Delta$, suggesting at least the distribution 
between surface and endosomal Gpa1 can be modulated in response to recycling efficiency (Figure $6 \mathrm{H})$. Alternatively, as Gpa1 is both palymitoylated and myristoylated (Song and Dohlman, 1996; Song et al., 1996), its ability to regulate endosomal lipids with $\mathrm{PI} 3 \mathrm{~K}$ may be required for its correct localisation.

Beyond the exact mechanism of Gpa2 inhibition, other important questions remain, such as the molecular function of Gpr1 and Ras2, which we confirmed are required for recycling (Figure 2C) whilst also being functionally associated with Gpa2 and glucose metabolism (Colombo et al., 1998, 2004). We speculate recycling inhibition via increased GPA2 expression is distinct from its role with Gpr1-Ras to induce cAMP signalling (Xue et al., 1998; Kraakman et al., 1999), as over-expression of Gpa2 does not inhibit Gpr1 function, instead it triggers increased Ras signalling and CAMP accumulation (Nakafuku et al., 1988). Our model would suggest clathrin mediated endocytosis of surface cargoes is counter-balanced by efficient Gpa1-PI3K recycling in glucose replete conditions. In glucose, the tuneable inhibitor of recycling Gpa2 is transcriptionally repressed, collectively maintaining high levels of surface proteins at the plasma membrane for optimal growth (Figure 5A). Upon glucose depletion, the Mig1-dependent increase in endocytosis via yeast AP180 adaptors (Laidlaw et al., 2020), would complement decreased recycling via the Glc7-Reg1 > Mig1 > GPA2 pathway to modulate the surface proteome to suit nutritional availability, increase lysosomal / vacuolar degradation and calibrate metabolic processes for cellular survival. G-protein regulators and $\mathrm{PI} 3 \mathrm{~K}$ orthologues are evolutionarily conserved (Pierce et al., 2002; Engelman et al., 2006), and although G-protein signalling is much more complex in animal cells, $\mathrm{Ga}_{\mathrm{s}}$ has been shown to regulate endosomal trafficking and surface protein function (Colombo et al., 1992, 1994; Beron et al., 1995; Zheng et al., 2004; Beas et al., 2012). Therefore, this mode of surface protein regulation in response to nutrition may be found in mammalian cells.

\section{METHODS}

\section{Reagents}

Supplemental tables are included to document use of plasmids (Supplemental Table S1) and yeast strains (Supplemental Table S2).

\section{Cell culture}

Yeast cells were cultured in either rich media (yeast extract peptone dextrose (YPD); $2 \%$ glucose, $2 \%$ peptone, $1 \%$ yeast extract) or synthetic complete minimal medium (SC; $2 \%$ glucose, yeast nitrogen base supplemented with amino acid / base dropout mixtures. Cultures were routinely porepared in serial dilution overnight so that cells were harvested for downstream experiemnts from early / mid-log phase log phase $\left(\mathrm{OD}_{600}=<1.0\right)$. For glucose starvation experiments, $2 \%$ glucose media was washed $3 x$ and exchanged with either identical media lacking any carbon source (no sugar) or media of the same receipe but instead containing $2 \%$ raffinose instead of glucose. KanMX and ClonNAT strain selections were performed in rich media containing $250 \mu \mathrm{g} / \mathrm{ml}$ geneticin/G418 (Formedium) or $150 \mu \mathrm{g} / \mathrm{ml}$ Nourseothricin (Jena Biosceince), respectively. GFP and mCherry fusions of SEC7 were created with a methotrexate cassette selected on $20 \mathrm{mM}$ methotrexate (Alfa Aesar) supplemented with $5 \mathrm{mg} / \mathrm{ml}$ sulphanilamide. The loxP flanked cassette was then excised by TEF1-Cre expression and plasmid removal, as described (MacDonald and Piper, 2015). Expression of plasmids from the CUP1 promoter in appropriate selective media was induced by the addition of Copper chloride (typically $20-100 \mu \mathrm{M}$ ).

\section{Confocal microscopy}

Cells were typically harvested from mid-log phase SC minimal media cultures and prepared for confocal microscopy on Zeiss laser scanning confocal instruments (LSM710 or LSM880 equipped with an Airyscan) using a Plan-Apochromat 63x/1.4 Differential Interference Contrast (DIC) objective lens. The fluorescent proteins GFP, mGFP and $\mathrm{mNeonGreen}$ were excited using the $488 \mathrm{~nm}$ line from an Argon laser their emission collected from 495- 550 $\mathrm{nm}$. Fluorescent protein mCherry and dye FM4-64 were excited using $561 \mathrm{~nm}$ line from a yellow DPSS laser and the emission collected $570-620 \mathrm{~nm}$.

\section{Apotome Structured IIlumination Microscopy}

Cells were imaged on a Zeiss Elyra 7 system using Plan-Apochromat 40x/1.4 oil objective lens. Multicoloured acquisition was performed sequentially to minimise cross talk between channels. The fluorescent images were capture on 2 PCO Edge sCMOS cameras attached to a DuoLink motorised dual camera adapter and the colour split using the secondary beam splitter BP420-480 + BP470-640 + LP740. The fluorescent protein mCherry was excited using $561 \mathrm{~nm}$ laser line and emission collected from 570 to $640 \mathrm{~nm}$. The fluorescent protein GFP was excited using 488nm laser line and emission collected from 490 to $570 \mathrm{~nm}$. Apotome acquisition was set to collect 5 phase images with $25 \mathrm{~ms}$ camera exposure time. Yeast cells were optical Z sections using step size optimised for "Leap" acquisition. For time lapse experiments $z$ stacks were collected with an interval of 4.3 seconds. Apotome phase images were processed using Zeiss Zen Black software set to 3D SIM Leap. The alignment between the colour channels was further improved by taking a $Z$ stack of multi-colour TetraSpec microspheres (ThermoFisher_ that was used to generate an alignment matrix using the "Channel alignment" tool in Zen Black and applied to the time lapse data. 


\section{Image analysis}

Micrographs were processed by Zeiss Zen and Fiji software. Images were processed using Zen software (Zeiss) and were further modified (e.g. coloured, merged) using Fiji.

\section{Yeast RNA extraction}

For gene expression analysis following glucose starvation wild-type cells were grown to mid-log phase in YPD before being split and incubated in $10 \mathrm{ml}$ YPD (dextrose) or $10 \mathrm{ml}$ YPR (raffinose) media for 1 hour prior to harvesting. For experiments to test the role of

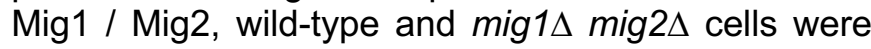
grown to mid-log phase in $10 \mathrm{ml}$ YPD before harvesting. Spheroplasting of harvested yeast cells was performed for 2 minutes in lysis buffer $(1 \mathrm{M}$ sorbitol $100 \mathrm{mM}$ EDTA, $0.1 \% \quad \beta$-mercaptoethanol) containing 25 units of zymolyase (Zymo Research). RNA extraction was performed with an RNeasy kit (QIAGEN) including additional DNasel treatment using a TURBO DNA-free kit (Invitrogen).

Quantitative reverse transcription PCR (RT-qPCR) cDNA was synthesised from $5 \mu \mathrm{g}$ extracted RNA with SuperScript IV reverse transcriptase (Invitrogen) using $50 \mathrm{ng} / \mu$ random hexamers and $10 \mathrm{mM}$ dNTPs. 5minute incubations at $65^{\circ} \mathrm{C}$ were carried out before $100 \mathrm{mM}$ DTT and Ribonuclease inhibitor added and the Superscript IV reverse transcriptase to initiate the qPCR reaction $\left(10\right.$ mins $23^{\circ} \mathrm{C} ; 10$ mins $55^{\circ} \mathrm{C} ; 10$ mins $80^{\circ} \mathrm{C}$ ) immediately. In order to amplify GPA1, oligonucleotides $361 \quad\left(5^{\prime}\right.$ ACATCGGCTCGTCCAAATTC) and 362 (5' TCTGGTCGTATTCACTCATTGC) were used. To amplify GPA2 oligonucleotides 365 CAATGGGCCTAACGCATCG) and 366 (5' GGGTCTGTAATTGGGCGAAG) were used. All experiments were compared to $A C T 1$ reference gene amplified by oligonucleotides 207 (5' CTCCACCACTGCTGAAAGAG) and 208 (5' GCAGCGGTTTGCATTTCTTG). Single product amplification was confirmed by PCR using genomic DNA as a template, and near- $100 \%$ amplification efficiencies were confirmed $(102.2 \pm 0.12 \%$ for GPA1, $101.5 \pm 0.03 \%$ for GPA2, and $100.6 \pm 0.08 \%$ for $A C T 1$ ) by duplicate $\mathrm{qPCR}$ reactions on a standard curve of known input quantity. qPCR reactions were performed on 20 ng cDNA, including relevant negative controls, in $20 \mu \mathrm{l}$ reactions containing $350 \mathrm{nM}$ of each primer, and $10 \mu \mathrm{l}$ Fast SYBR ${ }^{\mathrm{TM}}$ Green Master Mix (ThermoFisher Scientific). The QuantStudio 3 system (Thermofisher) was used for reactions under the following conditions: 40 cycles of $95^{\circ} \mathrm{C}$ for 1 second, 20 seconds $60^{\circ} \mathrm{C}$, before a continuous ramp from $60^{\circ} \mathrm{C}$ to $95^{\circ} \mathrm{C}$ at a rate of $0.1^{\circ} \mathrm{C} / \mathrm{S}$ for melt curve analysis. Expression of GPA1 and GPA2 under indicated conditions were quantified using the comparative Ct $(\Delta \Delta \mathrm{Ct})$ method, relative to the expression of the housekeeping gene ACT1 and normalized to control sample (glucose for raffinose comparisons and wild-type cells for comparison with mig1 $1 \Delta$ mig2 $\Delta$ mutants).

\section{Flow cytometry}

Fluorescence intensity of different strains stably expressing Ste3-GFP-DUb was measured using a CytoFLEX flow cytometer (Beckman Coulter) using a $488 \mathrm{~nm}$ excitation laser, and a 525/ $40 \mathrm{~nm}$ emission filter. Approximately 75,000 cells in culture medium per experiment were flowed at $\sim 600$ Volts with a simple gate (using forward/side scatter) used to count fluorescence-positive yeast cells. Gated cells were measured and plotted using FCS Express v7.04 (DeNovo software).

\section{FM4-64 recycling assay}

Cells were grown to mid-log phase in YPD, or SC-Ura minimal media when plasmid selection was necessary, before $1 \mathrm{ml}$ of cells $(O D=1.0)$ was harvested and incubated in $100 \mu \mathrm{l}$ YPD containing 40 $\mu \mathrm{M}$ FM4-64 dye (N-(3-Triethylammoniumpropyl)-4-(6(4-(Diethylamino) Phenyl) Hexatrienyl) Pyridinium Dibromide) dye for 8 minutes at room temperature. Cells were then washed $3 x$ in cold SC media, with each wash left for 3 minutes on ice, before final wash was concentrated in $100 \mu \mathrm{l} \mathrm{SC}$ media in preparation for flow cytometry. For raffinose and glucose starvation media, the same rich and SC media was used with glucose exchanged with either no sugar or $2 \%$ raffinose. $20 \mu \mathrm{l}$ of concentrated cells were brought up in $3 \mathrm{mls}$ room temperature SC medium, and approximately $1000-2500$ cells were flowed per second at $\sim 600 \mathrm{~V}$ using an LSR Fortessa instrument (BD Biosciences), whilst FM4-64 intensity was measured over a 10-minute period cytometry with excitation $561 \mathrm{~nm}$, laser emission filter $710 / 50$. Measurements from the $530 / 50 \mathrm{~nm}$ detector were also recorded for background autofluorescence.

\section{Image quantification for Mig1-GFP}

The nuclear signal of Mig1-GFP was calculated as a percentage of nuclear / total signal in the green channel, as shown in (Supplemental Figure S1). Briefly, whole cells were segmented based on DIC image using the Cell Magic Wand Plugin (Min = 8, Max $=300$, roughness $=2.0$ ) and used to calculate the total (nuclear plus cytoplasmic) signal for each cell in the Mig1-GFP / Green channel. The Nrd1-mCherry signal was used with otsu threshold to segment the nucleus based on the red channel and these regions of interest were applied to measure nuclear Mig1-GFP from the green channel.

\section{Statistical analyses}

Unpaired Student's $t$-tests were performed using GraphPad Prism v8.3.1. to compare the statistical significance between experimental conditions, with an asterisk $\left({ }^{*}\right)$ used to denote $p$-values of $<0.05$ or less, as mentioned in specific figure legends, or (ns) used to define differences that are not significant. 


\section{ACKNOWLEDGMENTS}

We would like to thank staff at the York Bioscience Technology Facility for technical assistance, including imaging team with microscopy, Karen Hogg with flow cytometry experiments and Sally James with qPCR analysis. We are grateful to Lois Weismann and Noah Steinfeld (University of Michigan) for reagents to manipulate yeast PI3-kinase activity. This research was supported by a Sir Henry Dale Research Fellowship from the Wellcome Trust and the Royal Society 204636/Z/16/Z (CM).

\section{DECLARATION OF INTERESTS}

The authors declare no competing interests. 
bioRxiv preprint doi: https://doi.org/10.1101/2021.04.02.438183; this version posted April 2, 2021. The copyright holder for this preprint (which was not certified by peer review) is the author/funder. All rights reserved. No reuse allowed without permission.

\section{REFERENCES}

Babst, M, Katzmann, DJ, Estepa-Sabal, EJ, Meerloo, T, and Emr, SD (2002a). Escrt-III: an endosome-associated heterooligomeric protein complex required for mvb sorting. Developmental Cell 3, 271282

Babst, M, Katzmann, DJ, Snyder, WB, Wendland, B, and Emr, SD (2002b). EndosomeAssociated Complex, ESCRT-II, Recruits Transport Machinery for Protein Sorting at the Associated Complex, ESCRT-II, Recruits
Multivesicular Body. Dev Cell 3, 283289.

Beas, AO, Taupin, V, Teodorof, C, Nguyen, LT, Garcia-Marcos, M, and Farquhar, MG (2012). Gas promotes EEA1 endosome maturation and shuts down proliferative signaling through interaction with GIV (Girdin). Mol Biol Cell 23, 4623-4634.

Beron, W, Colombo, MI, Mayorga, LS, and Stahl, PD (1995). In Vitro Reconstitution of Phagosome-Endosome Fusion: Evidence for Regulation by Heterotrimeric Gtpases. Arch Biochem Biophys 317, 337-342.

Best, JT, Xu, P, McGuire, JG, Leahy, SN, and Graham, TR (2020). Yeast synaptobrevin, Snc1, engages distinct routes of postendocytic recycling mediated by a sorting nexin, Rcy1COPI, and retromer. Mol Biol Cell 31, 944-962.

Binda, M, Péli-Gulli, M-P, Bonfils, G, Panchaud, N, Urban, J, Sturgill, TW, Loewith, R, and Virgilio, CD (2009). The Vam6 GEF controls TORC1 by activating the EGO complex. Mol Cell $35,563573$.

Blumer, KJ, and Thorner, J (1990). Beta and gamma subunits of a yeast guanine nucleotideBlumer, KJ, and Thorner, $\mathrm{J}(1990)$. Beta and gamma subunits of a yeast guanine nucleotide
binding protein are not essential for membrane association of the alpha subunit but are required for receptor coupling. Proc National Acad Sci 87, 4363-4367.

Bonfils, G, Jaquenoud, M, Bontron, S, Ostrowicz, C, Ungermann, C, and Virgilio, CD (2012). Leucyl-tRNA synthetase controls TORC1 via the EGO complex. Mol Cell 46, 105110.

Broggi, S, Martegani, E, and Colombo, S (2013). Live-cell imaging of endogenous Ras-GTP shows predominant Ras activation at the plasma membrane and in the nucleus in Saccharomyces cerevisiae. Int J Biochem Cell Biology 45, 384-394.

Buelto, D, Hung, C, Aoh, QL, Lahiri, S, and Duncan, MC (2020). Plasma membrane to vacuole traffic induced by glucose starvation requires Gga2-dependent sorting at the transGolgi network. Biol Cell 112, 349-367.

Burda, P, Padilla, SM, Sarkar, S, and Emr, SD (2002). Retromer function in endosome-toGolgi retrograde transport is regulated by the yeast Vps34 Ptdlns 3-kinase. J Cell Sci 115, 3889-3900.

Camilli, PD, Emr, SD, McPherson, PS, and Novick, P (1996). Phosphoinositides as Regulators in Membrane Traffic. Science 271, 1533-1539.

Chen, K, Healy, MD, and Collins, BM (2019). Towards a molecular understanding of endosomal trafficking by Retromer and Retriever. Traffic 20, 465-478.

Clement, ST, Dixit, G, and Dohlman, HG (2013). Regulation of Yeast G Protein Signaling by the Kinases That Activate the AMPK Homolog Snf1. Sci Signal 6, ra78-ra78.

Colombo, M, Mayorga, L, Casey, P, and Stahl, P (1992). Evidence of a role for heterotrimeric GTP-binding proteins in endosome fusion. Science 255, 1695-1697.

Colombo, MI, Mayorga, LS, Nishimoto, I, Ross, EM, and Stahl, PD (1994). Gs regulation of endosome fusion suggests a role for signal transduction pathways in endocytosis. J Biol Chem 269, 14919-14923.

Colombo, S et al. (1998). Involvement of distinct G-proteins, Gpa2 and Ras, in glucose- and intracellular acidification-induced cAMP signalling in the yeast Saccharomyces cerevisiae. Embo J 17, 3326-3341.

Colombo, S, Ronchetti, D, Thevelein, JM, Winderickx, J, and Martegani, E (2004). Activation Colombo, S, Ronchetti, D, Thevelein, JM, WinderickX, J, and Martegani, E (2004). Activation State of the Ras2 Protein and

DeVit, MJ, and Johnston, M (1999). The nuclear exportin Msn5 is required for nuclear export of the Mig1 glucose repressor of Saccharomyces cerevisiae. Curr Biol 9, 1231-1241.

Dietzel, C, and Kurjan, J (1987). The yeast SCG1 gene: A Ga-like protein implicated in the aand $\alpha$-factor response pathway. Cell 50, 1001-1010.

Dixit, G, Baker, R, Sacks, CM, Torres, MP, and Dohlman, HG (2014). Guanine Nucleotidebinding Protein $(\mathrm{G} \alpha)$ Endocytosis by a Cascade of Ubiquitin Binding Domain Proteins Is Required for Sustained Morphogenesis and Proper Mating in Yeast* ${ }^{\star}$. J Biol Chem 289, 15052-15063.

Engelman, JA, Luo, J, and Cantley, LC (2006). The evolution of phosphatidylinositol 3kinases as regulators of growth and metabolism. Nat Rev Genet 7, 606-619.

Finicle, BT, Jayashankar, V, and Edinger, AL (2018). Nutrient scavenging in cancer. Nat Rev Cancer 18, 619-633.

Fuente, G de la, and Sols, A (1962). Transport of sugars in yeasts II. Mechanisms of utilization of disaccharides and related glycosides. Biochim Biophys Acta 56, 49-62.

Heenan, EJ, Vanhooke, JL, Temple, BR, Betts, L, Sondek, JE, and Dohlman, HG (2009) Structure and Function of Vps15 in the Endosomal G Protein Signaling Pathway ,. Biochemistry-Us 48, 6390-6401.

Herman, PK, and Emr, SD (1990). Characterization of VPS34, a gene required for vacuola protein sorting and vacuole segregation in Saccharomyces cerevisiae. Mol Cell Biol 10, 6742-6754.

Ho, Y et al. (2002). Systematic identification of protein complexes in Saccharomyces cerevisiae by mass spectrometry. Nature $415,180183$.

Hong, S-P, Leiper, FC, Woods, A, Carling, D, and Carlson, M (2003). Activation of yeast Snf1 and mammalian AMP-activated protein kinase by upstream kinases. Proc National Acad Sci $100,8839-8843$
Hong, S-P, Momcilovic, M, and Carlson, M (2005). Function of Mammalian LKB1 and $\mathrm{Ca} 2+/$ Calmodulin-dependent Protein Kinase Kinase $\alpha$ as Snf1-activating Kinases in Yeast*. J Biol Chem 280, 21804-21809.

Johnston, M, Flick, JS, and Pexton, T (1994). Multiple mechanisms provide rapid and stringent glucose repression of GAL gene expression in Saccharomyces cerevisiae. Mol Cell Biol 14, 3834-3841.

Katzmann, DJ (2003). Vps27 recruits ESCRT machinery to endosomes during MVB sorting. J Cell Biology 162, 413423.

Katzmann, DJ, Babst, M, and Emr, SD (2001). Ubiquitin-Dependent Sorting into the Multivesicular Body Pathway Requires the Function of a Conserved Endosomal Protein Sorting Complex, ESCRT-I. Cell 106, 145155

Kihara, A, Noda, T, Ishihara, N, and Ohsumi, Y (2001). Two Distinct Vps34 Phosphatidylinositol 3-Kinase Complexes Function in Autophagy and Carboxypeptidase $Y$ Sorting inSaccharomyces cerevisiae. J Cell Biology 152, 519-530

Kraakman, L, Lemaire, K, Ma, P, Teunissen, AWRH, Donaton, MCV, Dijck, PV, Winderickx J, Winde, JHD, and Thevelein, JM (1999). A Saccharomyces cerevisiae G-protein coupled receptor, Gpr1, is specifically required for glucose activation of the cAMP pathway during the transition to growth on glucose. Mol Microbiol 32, 1002-1012.

Laidlaw, KME, Bisinski, DD, Shashkova, S, Paine, KM, Veillon, MA, Leake, MC, and MacDonald, C (2020). A glucose-starvation response governs endocytic trafficking and eisosomal retention of surface cargoes in budding yeast. J Cell Sci 134, jcs257733.

Laidlaw, KME, and MacDonald, C (2018). Endosomal trafficking of yeast membrane proteins. Biochem Soc T 46, 1551-1558.

Lang, MJ, Martinez-Marquez, JY, Prosser, DC, Ganser, LR, Buelto, D, Wendland, B, and Duncan, MC (2014). Glucose starvation inhibits autophagy via vacuolar hydrolysis and induces plasma membrane internalization by down-regulating recycling. J Biol Chem 289 ,
1673616747 .

$\mathrm{Li}, \mathrm{M}, \mathrm{Koshi}, \mathrm{T}$, and Emr, SD (2015). Membrane-anchored ubiquitin ligase complex is required for the turnover of lysosomal membrane proteins. J Cell Biology 211, 639652.

Lindmo, K, and Stenmark, H (2006). Regulation of membrane traffic by phosphoinositide 3kinases. J Cell Sci 119, 605-614.

Ludin, K, Jiang, R, and Carlson, M (1998). Glucose-regulated interaction of a regulatory subunit of protein phosphatase 1 with the Snf1 protein kinase in Saccharomyces cerevisiae. Proc National Acad Sci 95, 6245-6250.

Lundin, M, Nehlin, JO, and Ronne, H (1994). Importance of a flanking AT-rich region in target site recognition by the GC box-binding zinc finger protein MIG1. Mol Cell Biol 14, 1979-1985.

Lutfiyya, LL, Iyer, VR, DeRisi, J, DeVit, MJ, Brown, PO, and Johnston, M (1998). Characterization of three related glucose repressors and genes they regulate in Saccharomyces cerevisiae. Genetics 150, 1377-1391.

Ma, M, and Burd, CG (2019a). Retrograde trafficking and plasma membrane recycling pathways of the budding yeast Saccharomyces cerevisiae. Traffic.

$\mathrm{Ma}, \mathrm{M}$, and Burd, CG (2019b). Retrograde trafficking and quality control of yeast synaptobrevin, Snc1, are conferred by its transmembrane domain. Mol Biol Cell 30, 17291742.

Ma, M, Burd, CG, and Chi, RJ (2017). Distinct complexes of yeast Snx4 family SNX-BARs mediate retrograde trafficking of Snc1 and Atg27. Traffic 18, 134144.

MacDonald, C, Buchkovich, NJ, Stringer, DK, Emr, SD, and Piper, RC (2012a). Cargo ubiquitination is essential for multivesicular body intralumenal vesicle formation. Embo Rep 13, 331338 .

MacDonald, C, Payne, JA, Aboian, M, Smith, W, Katzmann, DJ, and Piper, RC (2015a). A Family of Tetraspans Organizes Cargo for Sorting into Multivesicular Bodies. Dev Cell 33, 328342 .

MacDonald, C, and Piper, RC (2015). Puromycin- and methotrexate-resistance cassettes and optimized Cre-recombinase expression plasmids for use in yeast. Yeast 32, 423438

MacDonald, C, and Piper, RC (2016). Cell surface recycling in yeast: mechanisms and machineries. Biochem Soc T 44, 474478.

MacDonald, C, and Piper, RC (2017). Genetic dissection of early endosomal recycling highlights a TORC1-independent role for Rag GTPases. J Cell Biol 8, jcb.201702177.

MacDonald, C, Shields, SB, Williams, CA, Winistorfer, S, and Piper, RC (2020). A Cycle of Ubiquitination Regulates Adaptor Function of the Nedd4-Family Ubiquitin Ligase Rsp5. Curr Biology $\mathrm{Cb}$

MacDonald, C, Stamnes, MA, Katzmann, DJ, and Piper, RC (2015b). Tetraspan cargo adaptors usher GPI-anchored proteins into multivesicular bodies. Cell Cycle 14, 36733678

MacDonald, C, Stringer, DK, and Piper, RC (2012b). Sna3 Is an Rsp5 Adaptor Protein that Relies on Ubiquitination for Its MVB Sorting. Traffic 13, 586598.

MacDonald, C, Winistorfer, S, Pope, RM, Wright, ME, and Piper, RC (2017). Enzyme reversal to explore the function of yeast E3 ubiquitin-ligases. Traffic 18,465484 .

MacGurn, JA, Hsu, P-C, Smolka, MB, and Emr, SD (2011). TORC1 Regulates Endocytosis via Npr1-Mediated Phosphoinhibition of a Ubiquitin Ligase Adaptor. Cell 147, 11041117.

Miyajima, I, Nakafuku, M, Nakayama, N, Brenner, C, Miyajima, A, Kaibuchi, K, Arai, K, Kaziro, Y, and Matsumoto, K (1987). GPA1, a haploid-specific essential gene, encodes yeast homolog of mammalian $\mathrm{G}$ protein which may be involved in mating factor signal transduction. Cell 50, 1011-1019.

Munn, AL, and Riezman, $\mathrm{H}$ (1994). Endocytosis is required for the growth of vacuolar $\mathrm{H}(+)$ ATPase-defective yeast: identification of six new END genes. J Cell Biology 127, 373-386.

Nakafuku, M, Obara, T, Kaibuchi, K, Miyajima, I, Miyajima, A, Itoh, H, Nakamura, S, Arai, K Matsumoto, K, and Kaziro, $Y$ (1988). Isolation of a second yeast Saccharomyces cerevisiae 
bioRxiv preprint doi: https://doi.org/10.1101/2021.04.02.438183; this version posted April 2, 2021. The copyright holder for this preprint (which was not certified by peer review) is the author/funder. All rights reserved. No reuse allowed without permission.

gene (GPA2) coding for guanine nucleotide-binding regulatory protein: studies on its structure and possible functions. Proc National Acad Sci 85, 1374-1378.

Nehlin, JO, and Ronne, $\mathrm{H}$ (1990). Yeast MIG1 repressor is related to the mammalian early growth response and Wilms' tumour finger proteins. Embo J 9, 2891-2898.

O'Donnell, AF, McCartney, RR, Chandrashekarappa, DG, Zhang, BB, Thorner, J, and Schmidt, MC (2015). 2-Deoxyglucose impairs Saccharomyces cerevisiae growth by stimulating Snf1-regulated and $\alpha$-arrestin-mediated trafficking of hexose transporters 1 and 3 . Mol Cell Biol 35, 939955.

O'Donnell, AF, and Schmidt, MC (2019). AMPK-Mediated Regulation of Alpha-Arrestins and Protein Trafficking. Int J Mol Sci 20, 515

Péli-Gulli, M-P, Sardu, A, Panchaud, N, Raucci, S, and Virgilio, CD (2015). Amino Acids Stimulate TORC1 through Lst4-Lst7, a GTPase-Activating Protein Complex for the Rag Family GTPase Gtr2. Cell Reports 13,17.

Pierce, KL, Premont, RT, and Lefkowitz, RJ (2002). Seven-transmembrane receptors. Nat Rev Mol Cell Bio 3, 639-650.

Reggiori, F, and Pelham, HRB (2002). A transmembrane ubiquitin ligase required to sort membrane proteins into multivesicular bodies. Nat Cell Biol 4, 117123.

Reidick, C, Boutouja, F, and Platta, HW (2017). The class III phosphatidylinositol 3-kinase Vps34 in Saccharomyces cerevisiae. Biol Chem 398, 677-685.

Robinson, JS, Klionsky, DJ, Banta, LM, and Emr, SD (1988). Protein sorting in Saccharomyces cerevisiae: isolation of mutants defective in the delivery and processing of multiple vacuolar hydrolases. Molecular and Cellular Biology 8, 49364948.

Santangelo, GM (2006). Glucose Signaling in Saccharomyces cerevisiae. Microbiol Mol Biol R 70, 253-282.

Sanz, P, Alms, GR, Haystead, TAJ, and Carlson, M (2000). Regulatory Interactions between the Reg1-Glc7 Protein Phosphatase and the Snf1 Protein Kinase. Mol Cell Biol 20, 13211328.

Sardana, R, and Emr, SD (2021). Membrane Protein Quality Control Mechanisms in the Endo-Lysosome System. Trends Cell Biol.

Schu, P, Takegawa, K, Fry, M, Stack, J, Waterfield, M, and Emr, S (1993). Phosphatidylinositol 3-kinase encoded by yeast VPS34 gene essential for protein sorting. Science 260, 88-91.

Schüller, H-J (2003). Transcriptional control of nonfermentative metabolism in the yeast Saccharomyces cerevisiae. Curr Genet 43, 139-160.

Selwan, EM, Finicle, BT, Kim, SM, and Edinger, AL (2016). Attacking the supply wagons to starve cancer cells to death. Febs Lett 590, 885907.

Shashkova, S, Wollman, AJM, Leake, MC, and Hohmann, S (2017). The yeast Mig1 transcriptional repressor is dephosphorylated by glucose-dependent and -independent mechanisms. Fems Microbiol Lett 364 .

Slessareva, JE, Routt, SM, Temple, B, Bankaitis, VA, and Dohlman, HG (2006). Activation of the Phosphatidylinositol 3-Kinase Vps34 by a G Protein a Subunit at the Endosome. Cel 126, 191-203.

Song, J, and Dohlman, HG (1996). Partial Constitutive Activation of Pheromone Responses by a Palmitoylation-Site Mutant of a G Protein a Subunit in Yeast †. Biochemistry-Us 35, 14806-14817.

Song, J, Hirschman, J, Gunn, K, and Dohlman, HG (1996). Regulation of Membrane and Subunit Interactions by N-Myristoylation of a G Protein a Subunit in Yeast. J Biol Chem 271, 20273-20283.

Spira, F, Mueller, NS, Beck, G, Olshausen, P von, Beig, J, and Wedlich-Söldner, R (2012). Patchwork organization of the yeast plasma membrane into numerous coexisting domains. Nat Cell Biol 14,640.

Stack, JH, Herman, PK, Schu, PV, and Emr, SD (1993). A membrane-associated complex containing the $\mathrm{Vps} 15$ protein kinase and the $\mathrm{Vps} 34 \mathrm{PI}$ 3-kinase is essential for protein sorting to the yeast lysosome-like vacuole. Embo J 12, 2195-2204.

Steinfeld, N, Lahiri, V, Morrison, A, Metur, SP, Klionsky, DJ, and Weisman, LS (2021) Elevating PI3P drives select downstream membrane trafficking pathways. Mol Biol Cell 32 , 143-156.

Stringer, DK, and Piper, RC (2011). A single ubiquitin is sufficient for cargo protein entry into MVBs in the absence of ESCRT ubiquitination. J Cell Biology 192, 229242.

Thevelein, JM (1994). Signal transduction in yeast. Yeast 10, 1753-1790.

Treitel, MA, Kuchin, S, and Carlson, M (1998). Snf1 Protein Kinase Regulates Phosphorylation of the Mig1 Repressor in Saccharomyces cerevisiae. Mol Cell Biol 18, 6273-6280.

Tu, J, and Carlson, M (1994). The GLC7 type 1 protein phosphatase is required for glucose repression in Saccharomyces cerevisiae. Mol Cell Biol 14,6789-6796.

Tu, J, and Carlson, M (1995). REG1 binds to protein phosphatase type 1 and regulates glucose repression in Saccharomyces cerevisiae. Embo J 14, 5939-5946.

Urbanowski, JL, and Piper, RC (2001). Ubiquitin Sorts Proteins into the Intralumenal Degradative Compartment of the Late-Endosome/Vacuole. Traffic 2, 622630.

Vallier, LG, and Carlson, M (1994). Synergistic release from glucose repression by mig1 and ssn mutations in Saccharomyces cerevisiae. Genetics 137, 49-54.

Vida, TA, and Emr, SD (1995). A new vital stain for visualizing vacuolar membrane dynamics and endocytosis in yeast. J Cell Biology 128, 779792

Westholm, JO, Nordberg, N, Murén, E, Ameur, A, Komorowski, J, and Ronne, H (2008). Combinatorial control of gene expression by the three yeast repressors Mig1, Mig2 and Mig3. Bmc Genomics 9, 601.
Whiteway, M, Hougan, L, Dignard, D, Thomas, DY, Bell, L, Saari, GC, Grant, FJ, O'Hara, P, and MacKay, VL (1989). The STE4 and STE18 genes of yeast encode potential $\beta$ and $Y$ subunits of the mating factor receptor-coupled $\mathrm{G}$ protein. Cell $56,467-477$.

Wiederkehr, A, Avaro, S, Prescianotto-Baschong, C, Haguenauer-Tsapis, R, and Riezman, H (2000). The F-Box Protein Rcy1p Is Involved in Endocytic Membrane Traffic and Recycling Out of an Early Endosome in Saccharomyces cerevisiae. J Cell Biology 149, 397-410.

Wollman, AJ, Shashkova, S, Hedlund, EG, Friemann, R, Hohmann, S, and Leake, MC (2017). Transcription factor clusters regulate genes in eukaryotic cells. Elife 6, e27451.

Wurmser, AE, and Emr, SD (2002). Novel Ptdlns(3)P-binding protein Etf1 functions as an effector of the Vps34 Ptdlns 3-kinase in autophagy. J Cell Biology 158, 761772.

Xu, P, Hankins, HM, MacDonald, C, Erlinger, SJ, Frazier, MN, Diab, NS, Piper, RC, Jackson, LP, MacGurn, JA, and Graham, TR (2017). COPI mediates recycling of an exocytic SNARE by recognition of a ubiquitin sorting signal. Elife 6, e28342.

Xue, Y, Batlle, M, and Hirsch, JP (1998). GPR1 encodes a putative G protein-coupled receptor that associates with the Gpa2p Ga subunit and functions in a Ras-independent pathway. Embo J 17, 1996-2007.

Yang, $X$ et al. (2020). TORC1 regulates vacuole membrane composition through ubiquitinand ESCRT-dependent microautophagy. J Cell Biol 219.

Zheng, B, Lavoie, C, Tang, T-D, Ma, P, Meerloo, T, Beas, A, and Farquhar, MG (2004). Regulation of Epidermal Growth Factor Receptor Degradation by Heterotrimeric Gas Protein Mol Biol Cell 15, 5538-5550. 